\title{
Pollen-based paleoclimate reconstructions of Beloslav Lake (Northeastern Bulgaria) during the last 6000 years using modern analog technique (MAT)
}

\author{
Палеоклиматични реконструкции в района на Белославското езеро \\ (Североизточна България) през последните 6000 години по данни \\ от спорово-поленовия анализ и метода на съвременните аналози
}

\section{Stoyan Vergiev \\ Стоян Вергиев}

Technical University of Varna, Department of Ecology and Environmental Protection, 1 Studentska St, 9010 Varna, Bulgaria; E-mail: stvergiev@gmail.com

\begin{abstract}
The aim of the present study is to reconstruct the palaeoclimate variables in the Beloslav Lake Region (Northeastern Bulgaria) during the last 6000 years, based on the pollen analysis from lacustrine core Bel-1 and using modern analog technique (MAT). Pollen data was used for reconstructions of four parameters: average annual temperature, average temperature of the warm and cold half-year and average annual precipitation.
\end{abstract}

Keywords: pollen, palaeoclimate reconstructions, modern analog technique, Northeastern Bulgaria.

\section{Въведение}

Изучаването на палеоклиматите придобива все по-голямо теоретично и практическо значение в контекста на съвременните глобални климатични промени. Сценариите за развитието на бъдещия климат се изготвят с помощта на цифрови математически модели, които използват тенденциите в промяната на климатичните променливи в пространството и времето (Vergiev, 2019). Извеждането на тези тенденции налага използването на точни количествени методи за статистическа обработка на фосилните данни, получени при спорово-поленовия анализ, на база на които да се извършат точни количествени реконструкции (Guiot, 1990; Vergiev, FilipovaMarinova, 2019).

В последните години методът на съвременните аналози (MCA) (Overpeck et al., 1985; Guiot, 1990) намира широко приложение за количествен анализ на фосилни данни от кватернерни седименти. Този метод се основава на зависимостта полен-климат, анализирана и остойностена на базата на съвременни повърхностни поле- нови проби и на съдържанието и процентното участие на поленови типове в тях, съотнесени към съвременните климатични данни в района на пробата (Vergiev, Filipova-Marinova, 2019). Климатичните променливи, свързани с найсходната съвременна проба, могат да бъдат асоциирани към времето и мястото на фосилната проба, която се реконструира в рамките на даден географски район (Sawada et al., 2004; Vergiev, Filipova-Marinova, 2019). По този начин, за разлика от класическите качествени интерпретации на поленовите спектри, чрез МСА може да се извърши количествена оценка и да се изведат точни данни за параметрите на палеоклиматите.

Целта на настоящото изследване е да се извърши реконструкция на средногодишната температура, средната температура на студеното полугодие, средната температура на топлото полугодие и средногодишнана сума на валежите за района на Белославското езеро през последните 6000 години чрез използване на метода на съвременните аналози и съпоставяйки данни от спорово-поленов анализ със съвременни климатични данни. 


\section{Материал и методи}

Анализирано е съдържанието на спори и полен в седиментите от сондаж Bel-1, прокаран в близост до северния бряг на Белославското езеро, при дълбочина на водния слой $2 \mathrm{~m}$. Изследваната дължина на сондажания разрез е $600 \mathrm{~cm}$.

На база на извършеното AMS радиовъглеродно датиране на 4 избрани проби от сондажа, беше създаден геохронологичен (възрастов) модел, представляващ линейна интерполация между възрастта на датираните нива и дълбочината (Bennett, 1994).

За извършване на реконструкцията на климатичните променливи беше използван методът на съвременните аналози (Overpeck et al., 1985; Guiot, 1990). Статистическата обработка на данните беше извършена със софтуерния продукт Polygon 2.3 (Nakagawa et al., 2002).
В настоящото изследване е използван съвременен калибрационен сет от Българското Черноморско крайбрежие, съдържащ данни за 421 съвременни поленови спектъра и съвременни климатични данни (Vergiev, 2019, 2021; Vergiev, Filipova-Marinova, 2019, 2020). Въз основа на факторен анализ на променливите и процентното участие на всеки тип в съвременните спектри се доказа надеждността на данните и възможността им да бъдат включени при сравнението с фосилните поленови спектри (Vergiev, FilipovaMarinova, 2019).

\section{Резултати и обсъждане}

Беше извършена реконструкция на климатичните параметри, като бяха използвани минимум 8 съвременни аналози за всяка фосилна проба (Nakagawa et al., 2002). Стойностите на средно-

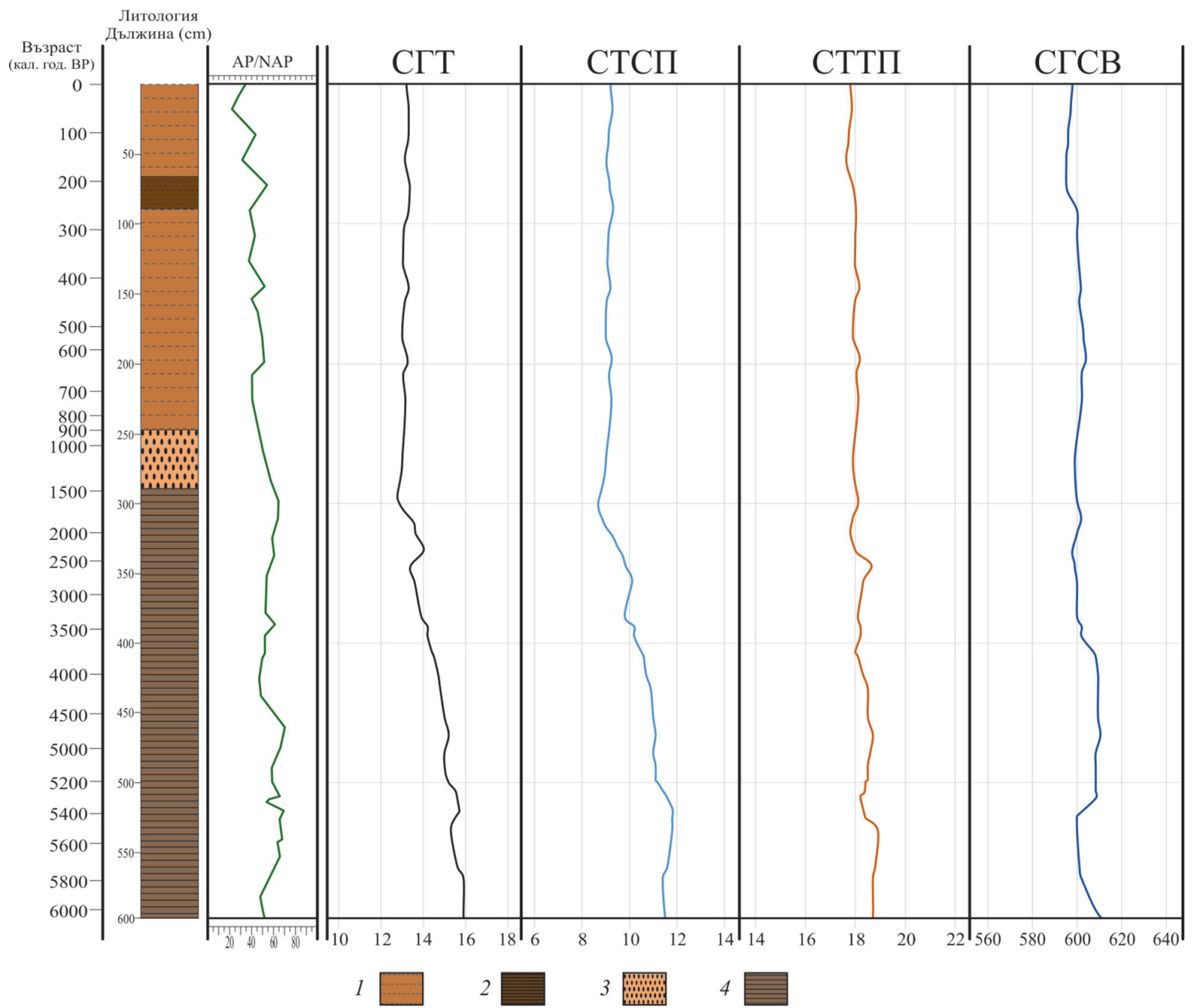

Фиг. 1. Реконструкция на палеоклиматичните променливи: СГТ - средногодишна температура $\left({ }^{\circ} \mathrm{C}\right)$; $\mathrm{CTCП} \mathrm{-} \mathrm{средна} \mathrm{тем-}$ пература на студеното полугодие $\left({ }^{\circ} \mathrm{C}\right)$; СТТП - средна температура на топлото полугодие $\left({ }^{\circ} \mathrm{C}\right)$; СГСВ - средногодишна сума на валежите $\left(\mathrm{mm} / \mathrm{m}^{2}\right)$; $\mathrm{AP}$ - дървесни и храстови таксони $(\%), \mathrm{NAP}$ - тревисти таксони $(\%), 1-$ бежовосиви глини, 2 - сиви глини, 3 - песъчливо-глинест слой, 4 - ламинирани 
годишната температура (СГТ), средната температура на студеното полугодие (СТСП), средната температура на топлото полугодие (СТТП) и средногодишната сума на валежите (СГСВ) бяха използвани за изчертаване на климатични криви (фиг. 1).

На база анализ на реконструираните данни и в съответствие с предходни изследвания (Vergiev, Filipova-Marinova, 2020) могат да бъдат отделени 3 времеви интервала, които демонстрират еднородност на климатичните променливи. През първия интервал (6000-5000 кал. год. ВР) са отчетени най-високи стойности на термалните параметри, което съвпада с холоценския климатичен оптимум. Реконструкцията на осреднената СГТ показва стойност $15,4 \pm 0,3{ }^{\circ} \mathrm{C}$. В този интервал е отбелязан и абсолютният максимум за изследвания период $-16,0 \pm 0,6{ }^{\circ} \mathrm{C}$. Годишната сума на валежите е относително висока, но е под предполагаемите средни стойности за атлантическия период. Получените стойности са идентични с данните от сондажи от СИ България (Vergiev, Filipova-Marinova, 2020).

Интервальт 5000-3000 кал. год. ВР се характеризира с динамика в стойностите на температурните параметри и тенденция на намаление. Осреднените стойности за интервала са: СГТ $-13,6 \pm 0,5{ }^{\circ} \mathrm{C}, \mathrm{CTC} \Pi-9,7 \pm 0,6{ }^{\circ} \mathrm{C}$, СТТП - $17,7 \pm 0,6{ }^{\circ} \mathrm{C}$. СГСВ има средна стойност $581 \pm 29 \mathrm{~mm} / \mathrm{m}^{2}$, като се отбелязва трайна тенденция на намаление.

Последният времеви интервал (3000 кал. год. ВР) се характеризира с относителна еднородност на климатичните параметри, които показват почти идентични стойности. Получената динамика различава кривите от тези, реконструирани за други сондажи от СИ България (Vergiev, Filipova-Marinova, 2020), но причината е в поголемия брой изследвани проби. Осреднените стойности за интервала са: СГТ $-12,8 \pm 0,5{ }^{\circ} \mathrm{C}$, СТСП - 8, $6 \pm 0,4{ }^{\circ} \mathrm{C}, \mathrm{CTT \Pi}-17,3 \pm 0,5^{\circ} \mathrm{C}$. СГСВ за този интервал е $540 \pm 38 \mathrm{~mm} / \mathrm{m}^{2}$.

\section{Заключение}

На базата на извършения спорово-поленов анализ на проби от сондаж Bel-1 от Белославското езеро бяха отделени 3 климатични интервала, за които бяха реконструирани климатичните променливи - средногодишна температура, средна температура на студеното полугодие, средна температура на топлото полугодие и средногодишна сума на валежите през последните 6000 години. През първия интервал (6000-5000 кал. год. ВР) са отчетени най-високи стойности на термалните параме- три, което съвпада с холоценския климатичен оптимум. Валежите са относително високи, но са под предполагаемите средни стойности за атлантическия период. Кривите на термалните параметри в интервала 5000-3000 кал. год. ВР показват динамика и тенденция на намаление. Последният времеви интервал (след 3000 кал. год. ВР) се характеризира с еднородност на климатичните параметри, които показват почти идентични стойности.

Благодарности: Част от научните изследвания, резултатите от които са представени в настоящата публикация, са извършени в рамките на присьщата на ТУ-Варна научноизследователска дейност, финансирана целево от държавния бюджет.

\section{Литература \\ References}

Bennett, K. 1994. Confidence intervals for age estimates and deposition times in late-Quaternary sediment sequences. - The Holocene, 4, 337-348; https://doi.org/ 10.1177/095968369400400401.

Filipova-Marinova, M., D. Pavlov, S. Vergiev, V. Slavchev, L. Giosan. 2013. Palaeoecology and geoarchaeology of Varna Lake, Northeastern Bulgaria. - C. R. Acad. Bulg. Sci., 66, 3, 377-392.

Guiot, J. 1990. Methodology of the last climatic cycle reconstruction in France from pollen data. - Palaeogeogr., Palaeoclimatol., Palaeoecol., 80, 49-69; https://doi.org/ 10.1016/0031-0182(90)90033-4.

Nakagawa, T., P. Tarasov, K. Nishidac, K. Gotanda, Y. Yasuda. 2002. Quantitative pollen-based climate reconstruction in central Japan: application to surface and Late Quaternary spectra. - Quaternary Sci. Rev., 21, 2099-2113; https://doi. org/10.1016/S0277-3791(02)00014-8.

Overpeck, J, T. Webb, C. Prentice. 1985. Quantitative interpretation of fossil pollen spectra: dissimilarity coefficients and the method of modern analogues. - Quaternary Res., 23, 87-108; https://doi.org/10.1016/0033-5894(85)90074-2.

Sawada, M., A. Viau, G. Vettoretti, W. Peltier, K. Gajewski. 2004. Comparison of North-American pollen-based temperature and global lake-status with CCCma AGCM2 output at 6 ka. - Quaternary Sci. Rev., 23, 225-244; https:// doi.org/10.1016/j.quascirev.2003.08.005.

Vergiev, S. 2019. GIS-based modern pollen-climate calibration set from eastern Bulgaria for 2017. - SocioBrains, 54, 202-208 (in Bulgarian with English abstract).

Vergiev, S. 2021. Modern pollen-climate calibration set from the Balkan Mountains region (Bulgaria) for 2020. - SocioBrains, 83, 92-98 (in Bulgarian with English abstract).

Vergiev, S., M. Filipova-Marinova. 2019. GIS-based model for analysis of modern pollen-climate relationship. - In: Scientific Works of the Union of Scientists in Bulgaria-Plovdiv. Series C. Technics and Technologies, 18, 240-246 (in Bulgarian with English abstract).

Vergiev, S., M. Filipova-Marinova. 2020. Pollen-based paleoclimate reconstructions of Northeastern Bulgaria during the last 7000 years using modern analog technique (MAT). - Rev. Bulg. Geol. Soc., 81, 3, 240-246 (in Bulgarian with English abstract). 